\title{
A passagem do sujeito antígo ao sujeito medieval e suas implicaçãos políticas: Aristóteles e Agostinho de Hipona
}

\section{The transit from the ancient "subiectum" - Subject - to the medieval one and their political implications: Aristotle and Augustine hippo}

\author{
Miguel Ángel Rossi ${ }^{1 *}$
}

\begin{abstract}
Resumo
A proposta do nosso trabalho tem como objeto de reflexão a passagem do sujeito antigo, na variante Aristotélica, para o sujeito medieval, na variante agostiniana e suas implicações políticas. Um dos aspectos teóricos de nosso trabalho é a categoria de espacialidade, constitutiva da polis grega como esfera pública, e a categoria de temporalidade e interioridade, própria do sujeito medieval. Outro aspecto relevante do trabalho consiste em mostrar como um significante próprio do medievo é a categoria de pecado original e as distintas variantes que dita categoria oferece à hora de pensar a cosmovisão política de Santo Agostinho. Por fim, indagaremos a respeito da desconstrução agostiniana do conceito de justiça clássica como virtude ético-política do mundo clássico e é, sobretudo, por este aspecto em particular que pode visualizar-se a nível teórico político o fim do mundo clássico.

Palvras-chave:
\end{abstract}

\begin{abstract}
Our work proposal has, as a reflection object, the transit from the ancient "Subiectum" - Subject - according to the Aristotelian variant, toward the medieval on, in its Augustinian varying and their political implications one o four works theoretical aspects is the category regarding to spaciousness, a Greek polis constitutive element as public sphere and the category regarding temporalness an inner nature, as peculiar ones to the medieval "Subiectum" - Subject - another outstanding aspect concerning our work consists of demonstrating, as a meaningful characteristic peculiar to the medieval persons is the original sin category and the different variants that such a category
\end{abstract}

\footnotetext{
* Professor titular da cátedra de Filosofia e Teoria Política. Universidade de Buenos Aires, Facultade de ciências sociais. Pesquisador do CONICET-IIGG. Doutor em Ciências Política, USP.Brasil
} 
imparts to the hour of thinking saint Augustine is political worldview, at last, we will inquire about classical justice concept Augustinian disconstruction as the classical world ethical-political virtue and it is, above all, through this view particularly that one can visualize, under the theoretical-political level the classical world end.

Key words: Acient Subject. Medieval Subject. Political implications. Aristotle. Augustine of Hippo.

Embora possa ser artificial o contraste entre Aristóteles e Agostinho², visto que Agostinho não conheceu os escritos aristotélicos, ao contrário da tradiçao platônica e ciceroniana, não devemos esquecer que o objetivo do nosso trabalho é focado na análise das implicações políticas da mudança do sujeito antigo para o sujeito medieval e nesse sentido, foi Aristóteles o referencial mais importante da filosofia política grega, especialmente por sua filosofía prática.

Também é importante ressaltar que o objetivo central do nosso trabalho é o aprofundamento da visão agostiniana mais do que da visão aristotélica. Assim, pretendemos pontuar os pressupostos políticos aristotélicos a partir dos quais podem ser corroborados o fechamento agostiniano com respeito à politicidade clássica.

\footnotetext{
Se bem situamos a Agostinho na patrística, como a síntese latina mais lograda da mesma, ao tempo que historicamente pertence à antiguidade tardia, usamos o termo medieval em um sentido amplo, interpretando por ele, um pensamento que é gerado pelo encontro entre a filosofia neoplatônica e as três grandes religiões do Livro. Nesse sentido, e apenas como uma exemplificação, podemos sustentar a convivência de vários séculos de filosofia antiga e da filosofia medieval, um exemplo ilustrativo seria Plotino (pensador pagão) e Orígenes (pensador cristão). Retomando a categoria da antiguidade tardia, Le Goff argumenta: "Esta precisión, Antigüedad tardía, me parece esencial, desde ahora ya no se habla de Bajo Imperio, sobreentendiendo con ello que es decadente. Implicaría un Alto Imperio supuestamente más evolucionado, que abarcaría desde Augusto hasta Constantino [...] Sin embargo, todo indica que era una potencia en pleno apogeo, que se prolongó desde Constantino (principios del siglo IV) hasta Justiniano (siglo VI), lo que suma un mínimo de 300 años" (Le Goff, 2004: 42).
}

218 - Universidade Católica de Pernambuco 
Com relaçao a Aristóteles, trabalharemos passagens chave de duas de suas principais obras: A Política e Ética a Nicômaco, no que diz respeito a Agostinho, vamos nos concentrar na Cidade de Deus, especialmente no livro XIX. Esse livro, asumindo un anacronismo, pode considerar-se um tratado de sociologia política.

A hipótese que sustenta nossa tarefa é que a ética em Aristóteles é uma dimensão da política. Em Agostinho, pode-se mostrar uma separação entre ética e política, se bem que pode ser uma exortação para o plano político, mas de nenhuma maneira intrínseca ao próprio conceito de politização.

Aprofundamos, portanto, nas ditas matrizes de pensamento enfatizando possíveis diferenças, mas não antes de esclarecer que há, pelo menos, um aspecto em comum entre os dois pensadores com relação a ser pensadores das crises terminais, tanto em relação ao colapso da polis, como de saqueio de Roma nas mãos de Alarico, na queda do Império Romano do Ocidente. A esse respeito não se pode perder de vista que a elaboração de A Cidade de Deus foi uma das principais motivações que desde uma retórica apologética ${ }^{3}$ fortemente desenvolvida por Agostinho tentou contrariar uma atmosfera pagã de acusação contra a doutrina cristã que consistia em culpabilizá-la pela queda de Roma, pelo abandono das divindades pagãs em favor do Deus cristão.

Para Aristóteles, e já anunciada à lógica imperial de Alexandre Magno, é relevante ressaltar a insistência do filósofo de continuar pensando a política com as categorias teóricas com as que abordou a polis grega, especialmente sobre a experiência ateniense e não em termos imperiais.

"He tomado por mi cuenta, carísimo hijo Marcelino, en esta obra a instancia tuya preparada y a ti debida con promesa mía, contra aquellos que anteponen sus dioses a su Fundador, la defensa de la gloriosísima Ciudad de Dios, ora en el actual discurso de los tiempos, ora en aquella estabilidad del descanso eterno, que ahora espera por la paciencia, hasta que la justicia se convierta en juicio,..." (ciu. 1, pról.). 
Ao falar do sujeito ${ }^{4}$ em Aristóteles, é fundamental notar que esta noção não se refere ao indivíduo tomado em um sentido ontológico proprio da Modernidade. Assim, o sujeito não é entendido em termos de subjetividade. Não obstante, se assumirmos uma abordagem foucaultiana ${ }^{5}$ para se referir ao sujeito como o que emerge de práticas sociais, ou como o sujeito entendido através de suas diferentes formas de sujeição ao longo da história, não haveria contradição ao considerar que o sujeito a que Aristóteles dedicou grande parte de seu pensamento não é outro senão a polis como sujeito e seus modos de subjetivação.

Mesmo Aristóteles entende a polis sob o regime de suas quatro causas: causa formal, o que corresponde ao regime político; causa material em relação à população, causa eficiente, de acordo com o legislador e a causa final, vinculada ao objeto da política como a boa vida. Assim, e como uma forma de restrição, poderíamos afirmar que o foco principal de Aristóteles é o homem, ou melhor, o grego, como um cidadão.

Para Agostinho, e assumindo uma hermenêutica hegelia$\mathrm{na}^{6}$, não temos problemas em admitir que o cristianismo trouxe o

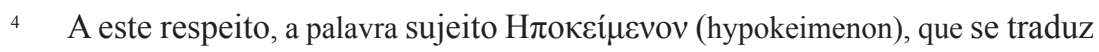
literalmente como "subjacente", foi traduzida para o latim como subiectum, daí sua derivação no sujeito. Além disso, hypokeimenon ligado também com a idéia de ousia (traduzido como substância), mas ao contrário deste, o hypokeimenon também podem assumir um significado que vai além de uma conotação material, como quando falamos de hypokeimenon do cosmos . Mas o fato é que a noção pode ser aplicada a diferentes entes particulares, como esta tabela, esta cadeira, este homem.

5 "Me propongo mostrar a ustedes cómo es que las prácticas sociales pueden llegar a engendrar dominios de saber que no sólo hacen que aparezcan nuevos objetos, conceptos y técnicas, sino que hacen nacer además formas totalmente nuevas de sujetos y sujetos de conocimientos" (Foucault, 1990:14).

6 "El principio jurídico está, empero, en relación inmediata con el principio universal. En la religión cristiana, por ejemplo, es principio universal, primero: que existe un espíritu que es la verdad, y segundo: que los individuos tienen un valor infinito y deben ser recibidos en la gracia de la espiritualidad absoluta. Consecuencia de esto es que el individuo es reconocido como infinito en su personalidad y como gozando de la conciencia de sí mismo, de la libertad. Este principio de que el hombre tiene 
registro da subjetividade combinado com a matriz do direito romano. Contudo, falar de subjetividade em um sentido mais forte vai ter que esperar para o século XII na ética da intenção de Abelardo ${ }^{7}$. Mas de qualquer maneira, é evidente que, no Cristianismo, refere-se a uma categoria tão importante como a vida eterna e a salvaçao individual.

Por outro lado, atendendo às Confissões, é importante considerar como é o próprio Agostinho que se declarou pessoa, constituiu-se pessoa a partir da alteridade divina. Isso inclui a forte noção do homem como imagem do divino e como a alma habita na Trindade em si.

Esta constituição da pessoa através da alteridade divina faz que a outridade divina atravesse a alma em sua própria constituição pelo infinito divino. A implicação dessa observação é que, ao contrário da experiência clássica, a experiência medieval estabelece uma interioridade infinita além do própio olhar de alma humana, pelo menos, não é possível saber ao certo os motivos de suas intenções. A esse respeito, a partir dessa perspectiva, a noção de tempo é fundamental para Agostinho, sobretudo como existenciário, para usar a terminologia de Heidegger, poder constituir a interioridade. Em contrapartida, trazem para o relacionamento que a noção de política por excelência do mundo clássico é o noçao de espacialidade: a espacialidade da ágora, academia, etc.

un valor infinito como hombre, no existe en las religiones orientales. Por eso sólo en el cristianismo son personalmente libres los hombres, esto es, aptos para poseer una propiedad libre" (Hegel, 1998:119)

7 A este respeito, não se pode entender dita ética da intencionalidade sem a revolução copernicana que Abelardo realiza em torno da categoria do pecado, na medida em que para pecar precisamos do conceito da intencinalidade dada pelo consentimento do sujeito. Assim, Abelardo argumenta: "Vicio es todo aquello que nos hace propensos a pecar. Dicho de otra manera, aquello que nos inclina a consentir en lo que no es lícito, sea haciendo algo o dejándolo de hacer. Por pecado entendemos propiamente este consentimiento, es decir, la culpa del alma por la que ésta es merecedora de la condenación o es rea de culpa ante Dios" $(2002: 3,8)$. 
Como dito acima, entende-se que, nesta vida terrena, para Agostinho, nunca poderemos saber se pertencemos à Cidade de Deus ou a Cidade do Diabo, já que é possível que, por trás das intenções de caridade, em cada vontade humana se esconda um profundo desejo oculto de orgulho, só percebido pelo olhar divino. A partir dessa perspectiva, tem sentido a frase agostiniana: $E u$ me tornei uma preocupação para mim (conf 10, 33, 50), enquanto a cristalização de um sujeito autorreflexivo de suas próprias intenções, um assunto ancorado no interior e fugindo em direção à transcendência, a experiência completamente estranha para Aristóteles, porque sua preocupação tinha sido a vida coletiva. A esse respeito, Arendt afirma:

\begin{abstract}
"En Agustín, la aspiración a la vida eterna como el summum bonum y la interpretación de la muerte como el súmmum malo llegó a su nivel de articulación más alto porque los combinó con el descubrimiento, propio de la nueva era, de una vida interior. Entendió que el interés exclusivo en este yo interior significaba: Me he convertido en una cuestión para mí mismo (quaestio mihi factus sum) -una cuestión que la filosofía, tal como entonces era enseñada y aprendida, jamás había planteado ni contestado-" (Arendt, 2010: 318).
\end{abstract}

Voltando à questão da passagem do sujeito antigo ao sujeito medieval, há muitos aspectos nessa oposição. Primeiro, devemos enfatizar que o foco da reflexão é a polis grega e o papel central da paideia como educação cívica. Além disso, para Aristóteles, a política tem um significado específico enquanto assimilação com a esfera pública e sua diferença qualitativa com o espaço doméstico. A esse respeito, como Arendt $^{8}$ bem explícitou,

\footnotetext{
8 "Lo que dieron por sentado todos los filósofos griegos, fuera cual fuera si oposición a la vida de la polis, es que la libertad se localiza exclusivamente en la esfera política, que la necesidad es de manera fundamental un fenómeno prepolítico, característico de la organización doméstica privada, y que la fuerza y la violencia se justifican en esta esfera porque son los únicos medios para dominar la necesidad- por ejemplo gobernar a los esclavos- y llegar a ser libre" (Arendt, 2010b:44).
} 
um cidadão grego nunca localiza o terreno da coerção no espaço público ou político, porque, por definição, pertence à esfera doméstica, caracterizada também pelo poder despótico. Assim, o espaço público se identifica com a liberdade, mas, acima de tudo, a liberdade cidadã reside no fato de que a comunidade política determina as leis a que os próprios cidadãos são submetidos, as leis criadas por eles mesmos. Em contraste, na Idade Média, vai entrar um significante primordial que fará à ligação entre política e coerção. Quanto à questão de que é a vontade política necessária coercitiva, um medieval não tinha sido lento em responder que foi por causa do surgimento do pecado original.

Destaquemos aspectos essenciais da citação precedente. Em primeiro termo, Agostinho faz referência à primeira ordem natural prévia ao pecado original. Ordem que supunha uma hierarquia pela qual Deus governava os homens, mas eles guardavam uma relação de horizontalidade entre si e não de hierarquia, o tempo que os homens deviam dominar os irracionais (animais). Em segundo lugar, a citação mostra como a autoridade política, entendida especificamente como exercício coercitivo, é aplicável ao homem pecador. Em outros términos, se sustenta que tem sido o surgimento do pecado original o que tem quebrantado, embora não anulado, a primeira ordem natural sabiamente estabelecida. A respeito, Truyo y Serra (1944) fazem referência a dois tipos de autoridade: a autoridade diretiva, própria do pai de família, sendo a família uma instituição que Agostinho pensa prévia ao pecado original, e uma autoridade coercitiva, própria da autoridade política. Desde nosso ponto de vista, concordamos em parte com o destacado estudioso, pois é evidente que autoridade em sentido coercitivo se entende a partir do pecado original, mas nos geram dúvidas a possibilidade de uma autoridade diretiva prévia ao pecado original, enquanto que a presença divina poderia invalidar tal necessidade. Em terceiro lugar, é interessante observar como, para Agostinho, não há uma ontologia do mal na natureza, pois toda natureza, ao haver sido criada pelo mesmo Deus, não pode ser compreendida como má: 
"Ninguna naturaleza, por lo tanto, es mala en cuanto naturaleza, sino en cuanto disminuye en ella el bien que tiene. Si el bien que posee desapareciera por completo, al disminuirse, así como no subsistiría bien alguno, del mismo modo dejaría de existir toda naturaleza, no solamente lo que inventan los maniqueos, en la que se encuentran aún tantos bienes que causa asombro su obstinada ceguera, sino que perecería toda naturaleza que cualquiera pudiera imaginar" (nat. b. 17).

Retomando os comentários de Truyol e Serra (1944), é relevante explicitar o marco teórico de dito estudioso ao mostrar como no "Hiponense" se situa três possíveis hermenêuticas em torno da política: a) interpretação positiva da política; b) interpretação negativa da política; e a c) interpretação eclética.

No que respeita à interpretação positiva, a mesma sustenta-se ao afirmar que o Estado interpretado como civitas tivesse existido prévio ao pecado original, pois da proliferação da vida familiar se infere certa necessidade de organização. Dita interpretação lembra a sequência que estabelece Aristóteles entre família, aldeia e polis. Não por casualidade, a hermenêutica tomista se baseia, em parte, em dita interpretação. (cf. Ullmann, 1992). Portanto, tal visão acentua que o pecado original perverte a ordem social, que, de todas as formas, tivesse existido. A esse respeito, nossa interpretação gira em torno a pontuar que dita interpretação identifica a dimensão social da natureza humana com a dimensão política, não existindo diferença alguma. Interpretação com a qual não concordamos, nem sequer para o caso de Aristóteles, pois, para o Estagirita, fica claro que uma coisa é a politicidade e outra diferente a sociabilidade ${ }^{9}$, que também é postulável ao terreno doméstico.

A Interpretação negativa da política põe o acento na radicalidade do pecado original e, em princípio, estaria em plena

\footnotetext{
9 O conceito de sociabilidade é aristotélico, mas nem toda comunidade é uma comunidade política. Assim, Aristóteles refere-se à comunidade doméstica, por exemplo, que pode existir entre homens e mulheres e até mesmo entre o amo e o escravo.
} 
sintonia com a citação precedente. Assim, a política como exercício coercitivo só tem razão de ser a partir da quebra do direito natural, sendo a consequência óbvia de tal perspectiva a exortação aos cristãos da não participação nos assuntos temporais. Agostinho é muito claro em tal questão ao exortar a colaboração dos cristãos em assuntos temporais, mesmo pondo o coração nos bens transcendentais.

A Interpretação eclética sustenta que autoridade coercitiva é produto do pecado original, mas em uma espécie de astúcia da razão hegeliana, é também uma reparação ou paliativo para que os homens não se agridam entre si. Ou seja, assegurar o ordenamento social em suas condições mínimas. Nessa perspectiva se compara o surgimento do Estado com a vinda do Cristo, enquanto dita encarnação teve lugar pelo pecado original e, ao mesmo tempo, constitui a redenção do mesmo. É certo que se bem é possível sustentar tal analogia, não se pode esquecer que, para Agostinho, a lógica dominandi não está, ao contrário de Lutero, ou, do agostinismo político, sacralizada. Assim, Agostinho contra-ataca a visão teológica do imperador tal qual era pensada pelos costumes romanos. Por outro lado, lembremos que para ele, quem encarna a vontade política pode ser tanto um cidadão da cidade de Deus como um cidadão da cidade do diabo, dado que não podemos escapar ao fato de enrolar-nos em uma destas duas cidadanias.

Retomemos a comparação com Aristóteles. Em primeiro lugar é fundamental tomar em consideração que, para ele, a politicidade constitui a diferença específica do homem, ou melhor dito, do cidadão grego. Só bastaria analisar a presente citação para sustentar a nossa afirmação.

"La razón por la cual el hombre es un ser social, más que cualquier abeja y que cualquier animal gregario, es evidente: la naturaleza, como decimos, no hace nada en vano, y el hombre es el único animal que tiene palabra. Pues la voz es signo de dolor y del placer, y por eso también la poseen también los demás animales, porque su naturaleza llega a tener sensación de dolor y de placer e indicársela unos a otros. Pero la palabra es para manifestar lo conveniente y lo perjudicial, así como lo justo 
y lo injusto. Y esto es lo propio del hombre frente a los demás animales: poseer el sólo, el sentido del bien y del mal, de lo justo y de lo injusto, y de los demás valores, y la participación comunitaria de estas cosas constituye la casa y la ciudad" (Pol. I, 1253a).

É importante observar a tradução do termo logos, mais que por razão, por palavra, sendo a palavra uma das possíveis modalidades na qual pode encontrar-se a razão. Mas precisemos dita questão fazendo nossos os argumentos do prestigioso estudioso Enrico Berti (2009).

Esse comentarista mostra como a tradução do homem como um animal racional no contexto da escolástica perdeu seu sentido da ratio como palavra. Portanto, a diferença específica do homem como homem, é precisamente a existência da palavra, só por isso segue-se que é um animal político. Por essa razão, como bem explica Berti, Aristóteles argumenta que os deuses também têm logos, mas não tem palavra, não precisam disso, principalmente por dois motivos: a) por sua própria autossuficiência e, b) porque, em conexão com a primeira declaração, não têm necessidade de viver em comunidade. Assim, o homem ocupa um lugar intermédio entre os animais (no sentido comum do termo) e os próprios deuses, mas, novamente, devemos salientar que a sua diferença específica é exatamente a palavra, a capacidade de gerar não apenas uma comunidade, mas uma comunidade deliberativa.

Voltemos a algumas categorias chave da citação acima. Em primeiro lugar, destaca-se a distinção que Aristóteles faz entre voz e palavra como fala. Com relação ao primeiro termo, é claro que Aristóteles não nega a possibilidade de expressão de certos animais, até mesmo alguma comunicação, mas se concentra no aspecto sensorial da alma (apenas a diferença específica dos animais). A palavra, por oposição à voz, já implica uma forma de razão, além da dimensão simbólica que caracteriza o aspecto deliberativo. Lembre-se que, para Aristóteles, uma característica natural do homem é o pensamento, entretanto as línguas são cria- 
ções arbitrárias (cf. Beuchot, 2004) ${ }^{10}$. E também pela palavra os homens geram o laço social, fundamento da comunidade política.

Em segundo lugar, aparece a referência à justiça, suprema arte que também fundamenta a comunidade política. Aprofundemos, portanto, este aspecto.

Na Ética a Nicômaco, Aristóteles distingue dois tipos de virtudes: dianoéticas e éticas. $\mathrm{O}$ denominador comum de ambas é o exercício da razão, só que, para o primeiro tipo de virtude, Aristóteles compreende o exercício da razão no seu caráter especulativo, é o exercício racional que precisamos dedicar tempo para as ciências teóricas, como é o caso da matemática. No caso das virtudes éticas, também para Aristóteles, temos exercício racional, mas aplicado a legislar a parte da alma sensível, é por isso que falamos de ética.

"Existen, pues, dos clases de virtud, la dianoética y la
ética. La dianoética se origina y crece principalmente por
la enseñanza, y por ello requiere experiencia y tiempo;
la ética, en cambio, procede de la costumbre, como lo
indica el nombre que varía ligeramente del de costumbre.
De este hecho resulta claro que ninguna de las virtudes
éticas se produce en nosotros por naturaleza, puesto que
ninguna cosa que existe por naturaleza se modifica por
costumbre (...) De ahí que las virtudes no se produzcan
ni por naturaleza ni contra naturaleza, sino que nuestra
naturaleza pueda recibirlas y perfeccionarlas mediante la
costumbre" (Eth. Nic. II, 1103a).

Para Aristóteles, a virtude suprema em relação às virtudes dianoéticas é a contemplação, enquanto a suprema virtude ética é a justiça. Além disso, encontram-se ligadas aos dois tipos de formas de vida. A vida contemplativa é sinônima, para Aristóteles, da vida filosófica, uma vida quase divina; enquanto uma vida ética vincula-se à comunidade política. Assim, ao contrário da contemplação, a justiça requer a ligação com os outros. Tam-

10 Especialmente o capítulo "A teoria da linguagem".

Ano $13 \cdot$ n. $1 \cdot$ jan./jun. $2013-227$ 
bém relacionada com as virtudes, Aristóteles traz à tona o assunto da felicidade. Ele acredita que a felicidade é o bem natual ao qual todos os homens tendem. Assim, podemos concluir que existem dois tipos de felicidade: a vida contemplativa e a vida da polis, justamente porque a polis é autárquica, só na polis os cidadãos podem alcançar suas habilidades superiores.

Por tudo isso, entendemos a forte ligação que Aristóteles estabelece entre ética e política, além de apontar que as duas dimensões são destinadas para refletir as ações humanas, ao contrário dos entes imutáveis, próprios das ciências teóricas, no campo da ação humana, objeto de ciência prática. Temos que deliberar, embora Aristóteles limita que a deliberação se concentra apenas no meio e não no fim, que é, por definição, natural.

Por outro lado, a deliberação forma parte da racionalidade prática, da racionalidade moral, própria do cidadão comun, ele pode diferenciar as ações justas das ações injustas, dependendo do momento, das circunstâncias, etc; mas a justiça é para Aristóteles um assunto inteiramente terrenal. É aqui, em particular, que assumimos que Agostinho termina com o espírito do mundo clássico, ao dissociar a forte ligação entre ética e política, específicamente para desconstruir o conceito de justiça como a fundação da comunidade política. Aprofundamos, neste último aspecto, mesmo a título de conclusão, pois acreditamos que, desde uma perspectiva política, o mesmo é o eixo central teórico de nosso trabalho.

Como anteriormente mencionamos, a categoria de justiça era para Aristóteles a categoria ético-política central, mas precisamos observar que esta opinião foi compartilhada por todo pensador político clássico. Platão, na República, também considera a virtude central, e o mesmo deve ser dito da impressão de Cícero, marca mais do que relevante para a compreensão hermenêutica de Agostinho, enquanto Agustinho assume aspectos da definição ciceroniana, claro que redefinindo fortemente seu sentido primordial. 
Desarrollada esta cuestión cuanto les parece suficiente, Escipión vuelve de nuevo a su discurso interrumpido, y recuerda y encarece una vez más su breve definición de república, que se reducía a decir que es una cosa del pueblo. Y determina al pueblo diciendo que no es toda concurrencia multitudinaria, sino una asociación basada en el consentimiento del derecho y en la comunidad de intereses. De su definición colige además, que entonces existe república, es a saber cosa del pueblo, cuando se la administra bien y justamente, ora por un rey, ora por unos pocos magnates, ora por la totalidad del pueblo (ciu. $2,21)$.

Nessa definição, existem três categorias relevantes para a hermenêutica Agostiniana: o conceito de povo, a noção de interesse e o conceito de justiça. Assim, Agostinho assume, de acordo com Cícero, que o sujeito de qualquer república como realmente existente, não é outro senão a existência de um povo, ao mesmo tempo, um povo não pode ser reduzido apenas a ser a soma de átomos individuais e, portanto, tanto Cícero como Agostinho, fazem uma distinção qualitativa entre povo e multidão. No que diz respeito à justiça, é claramente visto na citação acima, que sem justiça não há república porque não há povo, sendo esta uma constante durante toda a tradição republicana até o presente. $\mathrm{Ou}$ seja, a impossibilidade de repúblicas injustas. Finalmente, o conceito de "comunidade de interesse" é um constituinte do espírito romano em relação ao pensamento político. A partir dessa perspectiva, é sugestivo o comentário de Wolin:

La importancia asumida por el interés en la práctica y pensamiento político romanos sumaba un nuevo matiz de significado a la actividad política, y realzaba el carácter específico de la acción política. Los romanos habían advertido instintivamente que la legitimación del interés no sólo ocasionaba una forma limitada de acción, una especie de diplomacia interna, sino que también la multiplicidad de intereses presuponía el carácter incompleto de las soluciones para las cuestiones políticas. Si la actividad política se centraba alrededor de los intereses, los problemas concomitantes debían ser resueltos sobre la misma 
base; es decir, sobre la base de exigencias que divergían precisamente porque cada una poseía una determinada particularidad que la diferenciaba de las otras" (Wolin, 1993: 98).

Outra categoria chave do republicanismo é a noção de harmonia, para justificar uma analogia entre a melodia musical e a noção de concordância, típica de toda a República. Porque, assim como as notas de harmonia musical são diferentes e mutuamente complementárias, na república existem distintos estamentos sociais ainda convergentes entre si, por exemplo, o patriotismo sustentado pelo interesse no bem comum.

Agostinho exemplifica a noção de harmonia na disparidade, em analogia com a melodia musical:

"Y lo que los músicos llaman armonía en el canto, esto era en la ciudad la concordia, vínculo el más estrecho y suave de consistencia en toda república, la cual sin la justicia es de todo punto de vista imposible que subsista'. Diserta luego larga y bellamente sobre la necesidad de la justicia para la ciudad y sobre los daños que se siguen de su ausencia" (ciu. 2, 21).

Agostinho, seguindo a Cícero, diz que a perda do bem comum implica a morte da república e o maior tipo de injustiça enquanto instauração do terreno do arbitrário ou particular, como por exemplo, são as tiranias ou as facções. Com respeito a este aspecto é muito interessante a observação de Adams (1971) entanto enfatiza seguindo fielmente a Agostinho, que nem o mesmo populus é mais povo si é injusto, já que em tal caso não é uma multidão unida em irmandade por um direito de sentido comum e um interesse comunitário. Inclusive, para um povo injusto, ou melhor dito, uma multidão, dito comentarista continua argumentando que Agostinho não encontrou outro termo atual para usar mais que o termo grego de tirano. Dita observação nos interessa porque, de alguma forma, anuncia o que, em termos teóricos políticos modernos costumam denominar-se a tensão entre República e democracia. Pois ao tratar o povo como tirano, Agostinho faz 
referência implícita à ideia de massa, ou seja, se bem é uma multidão e está orientada a um interesse particular, ou de uma facção.

Aprofundemos agora, sobre um aspecto fundamental em que as diferenças entre Cícero e Agostinho são insanáveis. A denúncia de Cícero em relação à destruição da república romana gira em torno da quebra do direito e à corrupção dos costumes cidadãos. É indispensável ter claro que tal denúncia descansa para o jurista romano nas ações dos homens como únicos sujeitos responsáveis; e não por causa do culto aos deuses romanos, como menciona Agostinho junto com seu contexto. O Hiponense explicita tal questão porque lhe interessa introduzir o problema da idolatria formando um corpo em comum com a dimensão ética. Esse é o eixo essencial do seu discurso apologético. E é a partir dele que interpretará o conceito de "justiça" já não em chave humana, senão em termos cristãos e transcendentes.

Dessa forma, Agostinho introduz a noção de verdadeira justiça, e fica claro que a dimensão teológica se situa unicamente em Agostinho e, ao introduzir dita categoria como fundamento da república, maximiza sua polêmica com os pagãos de seu tempo. Por essa razão introduz a questão idolátrica, que era alheia a Cícero como o motivo principal da decadência romana. A esse respeito, Marshall (1952) sustenta que Agostino aceita a interpretação ciceroniana de iuris consensus como justiça. Mas enfatiza que o Hiponense recusa o conceito de justiça como um fator integrante do estado romano; isso explica a ausência da frase iuris consensus. O mesmo autor afirma, também, que a conexão entre ius e iustitia pode ser também ciceroniana, mas não resta dúvida - e nós concordamos nisso - que, quando isutícia é especificada como "verdadeira justiça", a única assinatura possível é a de Agostinho.

"[...] donde no hay verdadera justicia no puede darse verdadero derecho./ Como lo que se hace con derecho se hace justamente, es imposible que se haga con derecho lo que se hace injustamente. En efecto, no deben llamarse derecho las constituciones injustas de los hombres, puesto que ellos mismos dicen que el derecho mana de la fuente de la justicia y que es falsa la opinión de quienes 
sostienen torcidamente que es derecho lo que es útil al más fuerte. Por tanto, donde no existe verdadera justicia no puede existir comunidad de hombres fundado sobre derechos reconocidos, y, por tanto, tampoco pueblo, según la definición de Escipión o de Cicerón. Y si no puede existir el pueblo, tampoco la cosa del pueblo, sino la de un conjunto de seres que no merece el nombre de pueblo. Por consiguiente, si la república es la cosa del pueblo y no existe pueblo [...] síguese que donde no hay justicia no hay república" (ciu. 19, 21).

É desde a noção de "verdadeira justiça" que Agostinho argumenta que em Roma nunca existiu uma autêntica República porque nunca reinou uma verdadeira justiça. Sem embargo, acreditamos que a intenção Agostiniana não é invalidar a República romana enquanto tal, pelo menos, a relacionada com a antiga república à que lhe assigna - como temos referenciado anteriormente - certas virtudes. Sua intenção é mostrar, em primeiro termo, a injustiça que supõe render culto a deuses de barro e pedra que, por outra parte, eram os desuses tutelares que emigraram de Troia a Roma. Lembremos que a constituição romana limitava o acionar das injúrias dos poetas aos cidadãos, não assim a seus deuses. Este é um ponto decisivo para a valorização positiva de Agostinho a respeito da constituição romana; mas, ao mesmo tempo, dita constituição careceu de uma sabedoria que estendesse seus domínios à simbologia e ao acionar dos próprios deuses. Será, então, o Hiponense o que agrega dito extra, invertendo a acusação dos pagãos aos cristãos. Em tal sentido, adorar deuses tutelares é introduzir na república a máxima injustiça, com a nefasta consequência da destruição da mesma.

Em segundo lugar, ele está interessado em distinguir a profunda diferença entre a república romana, e toda possível república terrena, a respeito da cidade de Deus. Claramente, para Agostinho, nesta vida terrena é impossível cumprir a verdadeira justiça, embora isso não signifique necessariamente que temos que respeitar os valores injustos.

No Livro XIX, Agostinho retoma a questão de haver ou não a República Romana; ele o faz explicitamente para acabar 
com essa polêmica que tinha aberto no segundo livro da Cidade de Deus. A esse respeito, uma vez que é essencial a contribuição de Adams (1971), que enfatiza a mudança mental de Agostinho para escrever o livro XIX com relação ao livro II. Esse comentarista argumenta que a posição teórica de Agostinho pode ser vista como muito mais moderada, enquanto a original, dado que ele não estava muito interessado em desacreditar as reivindicações dos romanos como agentes de uma missão histórica sobre-humana, além de nossa visão, que considera que Agostinho redefine as virtudes cívicas dos romanos também como legado civilizatório para a humanidade. De qualquer forma, há certeza de que o Livro XIX, ao contrário do primeiro corpo de sua monumental obra, vai muito além de uma intenção simplesmente apologética e é claro que delineia tanto uma teologia da história, bem como o que atualmente podemos chamar algo próximo a uma teoria sociológica, específicamente no livro XIX.

"Este es precisamente el lugar propio para decir, lo más concisa y claramente que pueda, lo que prometí en el libro II de esta obra. Y es mostrar que, según las definiciones de que Escipión se sirve en los libros Sobre la república de Cicerón, no ha existido nunca la república romana" (ciu. 19, 21).

Dita citação reforça o que estamos sustentando em nosso trabalho. Agostinho usa o conceito de justiça como foi recebido pela tradição neoplatônica, especialmente a partir da hermenêutica da República de Platão. Lembre-se que Platão definiu a justiça, como fazer o que corresponde de modo concorde à natureza, sendo a natureza diferente para cada estamento social, mas também dar a cada estamento o que lhe corresponde pela natureza. Agostinho apropria-se de tal definiçao, mas imprimindo-lhe sua própria marca:

"Ahora bien, la justicia es la virtud que da a cada uno lo suyo. ¿Qué justicia es esta que aparta al hombre del Dios verdadero y lo somete a los inmundos demonios? ¿Es acaso dar a cada uno lo suyo? ¿O es que quien quita la heredad a quien la compró y la da a quien no tiene 
derecho a ella, es injusto; y quien se quita a sí mismo al Dios dominador y creador suyo y sirve a los espíritus malignos, es justo?" (ciu. 19, 21).

A categoria de verdadeira justiça, como já dissemos várias vezes - subsume a definiçao ciceroniana de justiça, mas Agostinho a eleva a um plano superior. Nesse sentido, parece pertinente a observação de Etienne Gilson:

"Cuando habla de una ciudad humana, Agustín piensa ante todo en Roma y en su historia, tal como se la habían enseñado los escritores latinos. Si ha podido refutar el cargo dirigido contra la iglesia, de haber causado la ruina de Roma, es porque -según vimos- el mismo Salustio ${ }^{11}$ había tenido a Roma como arruinada por sus propios vicios desde antes del nacimiento de Cristo. Preguntándose en qué momento de su historia mereció el nombre de ciudad, también entonces apela a una definición pagana de la ciudad. Así juzgando a la sociedad pagana en nombre de las normas que ella misma había poseído, se inspira en reglas que ella no podría recusar" (Gilson, 1954: 49).

Compartilhamos a posição de Gilson no que respeita a que Agostinho utiliza a definição ciceroniana de justiça, mas como expressamos acima, acreditamos que o conceito agostiniano de Verdadeira justiça é utilizado por Agostinho para desacreditar qualquer república terrena e nao só a república romana, obviamente julgada em termos de "verdadeira justiça" e também condenar o pecado da idolatria.

Se enfatizarmos uma perspectiva apologética, é fácil argumentar que, para Agostinho, Roma era uma verdadera república, porque ele queria tomar como própria a denúncia de Cicero da corrupção dos costumes romanos e da perda da república, muito antes do surgimento do cristianismo. Se enfatizarmos uma perspectiva ontológica ou metafísica, a única república que merece o

\footnotetext{
11 Grande historiador romano que Agostinho toma como autoridade 234 - Universidade Católica de Pernambuco
} 
nome é o Civitas Dei, porque só lá, e não nas repúblicas terrenas reina a "verdadeira justiça".

O problema surge quando consideramos a proposição agostiniana de uma perspectiva absoluta. Se isso é assim, é claro que os laços sociais que se estabelecem em torno do conceito da verdadeira justiça não são possíveis na sociedade terrena. Assim, podemos incorrer em um desprezo pela questão terrena, que Agostinho tenta evitar a todo custo. Dessa forma, a insistência agostiniana que a Cidade de Deus, bem como a Cidade do diabo são categorias espirituais e, portanto, não podem localizar-se geograficamente ou institucionalmente. Agostinho enfatiza que, nas sociedades terrenas, coabitam os dois tipos de cidadãos. Além disso, não se esqueça da avaliação positiva que Agostinho faz sobre as instituições humanas. A partir dessa perspectiva é que os Estados podem ser avaliados como dispositivos instrumentais, garantidores da ordem e da paz na terra. Paz, que Agostinho não se cansa de insistir, conveniente para os dois tipos de cidadãos.

A posteriori, Agostinho redefine a definição clássica de república baseada no conceito de justiça, usando uma nova categoria como fundamento de toda república: a noção de amor, em estreita relação com a unificação de um "povo" pela escolha do objeto de amor. É por essa Razão que a nova definição utiliza mais o conceito de povo do que o conceito de república. Basta trazer sua nova definição de república para dar conta da dita mudança fundamental que vai gerar importantes implicações para a teoria política, enquanto a noção de república pode ser interpretada de uma forma mais relaxada, mesmo obrigando à posibilidades de república injustas.

"El pueblo es un conjunto de seres racionales asociados por la concorde comunidad de objetos amados; para saber qué es cada pueblo, es preciso examinar los objetos de su amor. No obstante, sea cual fuere su amor, si es un conjunto, no de bestias, sino de seres racionales, y están ligados por la concorde comunión de objetos amados, puede llamarse, sin absurdo ninguno, pueblo" (ciu. 19, 24). 
No entanto, quando ele assume o conceito de amor como o fundamento de toda a república possível, não está falando do amor cristão, o amor como caridade, ele assume o amor na clássica visão de eros, misturada com a categoria medieval da vontade como falculdade de querer.

Se existe uma categoria privilegiada para o nosso grande pensador, certamente a noção de vontade pode competir pelo primeiro lugar. Agostinho define a vontade como a facultade do querer, e nela reside a dimenção do livre arbítrio. Como facultade do querer, a vontade ${ }^{12}$ sempre vai orientar-se em relação a um objeto considerado o objeto supremo de seu amor ${ }^{13}$. Essa é a razão por que, para Agostinho, os cidadãos da cidade de Deus têm a Deus como seu supremo objto de amor e os cidadãos da cidade do diabo têm ao mundo (absolutizam os bens temporais).

Mas tanto num caso como no outro, o que determina ambas as cidades e cidadãos é a categoria do amor. Claro que o tipo de amor dos cidadãos da cidade terrena não tem a dignidade do amor celestial. Este é um ponto chave, porque precisamente, por essa razão, Agostinho argumentou, sem contradição, a existência de repúblicas injustas que têm o único propósito de absolutizar os bens temporais. Por essa razão, Agostinho vai terminar por dissociar, como mencionamos acima, o campo da ética daquele da política.

"Pero no por eso diré que no es pueblo, ni que su asunto primario no es la República, entretanto que se conser-

12 Ao se aprofundar na categoria de amor, é essencial distinguir suas diferentes formas, para ver como eles jogam na estrutura da Cidade de Deus. É neste sentido que a obra de Rivera Ventosa é muito interessante, já que ele está explicitando diferentes formas fundamentais do amor utilizadas por Agostinho. Estas são: amor afetuoso, exemplificado na relação de Agostinho com a mãe, o amor ágape, amor amizade, o amor da ordem, o amor Eros. Ventosa Rivera argumenta, e nós concordamos, que essas formas mencionadas, apenas os três últimos desempenham um papel central na Cidade de Deus (cf. Rivera Ventosa De, 1967

13 Essa visão de mundo já está presente em seus primeiros escritos de Agostinho, como por exemplo, o livre arbitrio 
vare cualquiera congregación organizada y compuesta de muchas personas, unida entre sí con la comunión y concordia de las cosas que ama. Lo que he dicho de este pueblo y de esta República, entiéndase de los atenienses, o de otra cualquiera de los griegos, y lo mismo la de los egipcios, y de aquella primera Babilonia de los asirios, cuando en sus Repúblicas estuvieron sus imperios grandes o pequeños, y eso mismo de otra cualquiera de las demás naciones" (ciu. 19, 24).

Como conclusão do nosso trabalho, apenas o suficiente para resumir algumas implicações políticas dessa passagem do sujeito antigo ao medieval que foram trabalhados ut supra. Pode-se afirmar, primeiro: a cristalização de um sujeito auto-reflexivo ancorado em sua interioridade em vôo para a transcendência e, conseqüentemente, a relativização da esfera pública e do primado do homem como cidadão. Segundo, a quebra do vínculo entre ética e política como esferas de uma mesma totalidade, embora Agostinho acredite que a ética pode ter um papel exortatório em relação à política. Terceiro, a quebra da noção de justiça como a fundação da república na terra e, assim, o fechamento do mundo clássico.

Finalmente, não podemos deixar de mencionar que Agostinho nunca entrou na política como um campo específico de estudo. Assim, sua visão de mundo político só pode ser compreendida em referência a sua visão de mundo teológica. A esse respeito, devemos esperar a hermenêutica de Tomás sobre Aristóteles para relativizar uma forte teocracia política. No entanto, não devemos cometer o erro de colocar a Cidade de Deus na Igreja e a Cidade do Diabo no Estado. O Hiponense, é claro em afirmar que estas categorias são jogadas em um nível espiritual e, portanto, não podem ser localizadas institucional ou geograficamente, assim, alertando que as sociedades terrenais, com suas leis e instituições são boas para os dois tipos de cidadãos. 


\section{Bibliografia}

Abelardo, P. (2002). Conócete a ti mismo. Madrid. Tecnos.

Adams, J. D. (1971.) The "populous" of Agustine and Jerome. A Study in the Patristic Sense of Community. New Haven and London. Yale Univ. Press.

Arendt, H. (2010a). La vida del espíritu. Buenos Aires. Paidós.

Arendt, H. (2010b). La condición humana. Buenos Aires. Paidós.

Aristóteles (1982). Ética Nicomaquea. Madrid. Gredos.

Aristóteles (1989). La Política. Madrid. Centro de Estudios Constitucionales.

BerTi, E. (2009). En el principio era la maravilla. Madrid. Gredos.

Beuchot, M. (2004). Ensayos marginales sobre Aristóteles. México. UNAM.

Foucault, M. (1990). La verdad y las formas jurídicas. México. Gedisa.

Gilson, É. (1954). Las metamorfosis de la Ciudad de Dios, Buenos Aires. Troquel.

Hegel, G. W. F. (1998). Lecciones sobre la filosofía de la historia universal (I).Barcelona. Atalaya.

Le Goff, J. (2004). En busca de la Edad Media. Buenos Aires. Paidós.

MagnavaccA, S. (2006). "Elementos fundamentales para una lectura actual de san Agustín": Etiam, 1, 11-35.

Marshall, R. T. (1952). Studies in the Political and Socio-Religious Terminology of the "Civitate Dei". Washington. Catholic University of America Press.

Parodi, M. (2011). El paradigma filosófico agustiniano. Buenos Aires. Miño y Dávila.

Rivera De Ventosa, E. (1967). "La estructura de la Ciudad de Dios, a la luz de las formas fundamentales del Amor" Agustinus, vol. 12, n. 196, 355-374.

Truyol y Serra, A. (1944). El Derecho y el Estado en San Agustín. Madrid. Editorial Revista de Derecho Privado. 